\title{
Roberta Trapè
}

\section{Building Empathy and Intercultural Citizenship through a Virtual Exchange Project}

\begin{abstract}
I: L'articolo esplora possibilità di creare uno spazio che sviluppi l'empatia nell'insegnamento delle lingue e culture straniere. Si basa su studi sull'empatia (Deardoff 2006; Bloom 2016; Guntersdsorfer \& Goulbeva 2018), sulle idee di competenza e cittadinanza interculturale (Byram 1997, 2008; Byram et al. 2017), e sull'idea di "terzo spazio" come teorizzata da Edward Soja (1996), e mette in evidenza l'importanza delle emozioni nell'educazione interculturale. Se consideriamo il fenomeno del cosiddetto "spatial turn" nella sua dimensione pedagogica, la concettualizzazione proposta da Soja di un "terzo spazio" può essere connessa allo sviluppo di uno spazio di apprendimento alternativo per interazioni interlinguistiche e interculturali, ampliato e delineato da relazioni sociali, pianificato attraverso collaborazioni cross-culturali, e costruito attraverso scambi virtuali. Uno spazio che è costruito sulla base delle esperienze vissute di coloro che lo popolano può favorire l'empatia. L'autrice presenta in sintesi uno scambio virtuale di cittadinanza interculturale tra l'Italia e gli Stati Uniti, dove uno degli obiettivi principali è lo sviluppo dell'empatia e la verbalizzazione della comprensione emotiva da parte degli studenti.
\end{abstract}

Abstract II: The article explores possibilities of creating a space to develop empathy in teaching foreign languages and cultures. It draws upon studies on empathy (Deardoff 2006; Bloom 2016; Guntersdsorfer \& Goulbeva 2018), the ideas of intercultural competence and citizenship (Byram 1997, 2008; Byram et al. 2017) and "thirdspace" as theorised by Edward Soja (1996), highlighting the importance of emotions in intercultural education. If we consider the phenomenon of the "spatial turn" in its pedagogical dimension, Soja's conceptualisation of a "thirdspace" can be connected to the development of an alternative learning space for inter-linguistic and intercultural interactions, enhanced and shaped by social relationships, designed through cross-institutional collaborations, and achieved through virtual exchanges. A space that is built in terms of the lived experiences of those who inhabit it can foster empathy. The author presents a virtual exchange project for intercultural citizenship between Italy and the U.S.A. where one of the key objectives is building empathy and allowing the verbalisation of students' emotional understanding. 


\section{Introduction: should empathy be taught in intercultural education? ${ }^{1}$}

The article explores possibilities of creating a space to develop empathy through intercultural competence in teaching foreign languages, cultures and literatures. It draws upon studies on empathy (Deardoff 2006; Bloom 2016; Guntersdsorfer \& Goulbeva 2018), the ideas of intercultural competence and citizenship (Byram 1997, 2008; Byram et al. 2017) and of "thirdspace" as theorised by Edward Soja (1996), highlighting the importance of emotions in intercultural education. A telecollaborative project between Italy and the U.S.A., where one of the key objectives is the verbalisation of students' emotional understanding and feelings, is presented in synthesis. Should empathy be taught in schools and higher education? The opponents offer two principal reasons: empathy cannot be taught; empathy is not related to academic achievement. In truth, there are in fact doubts about whether empathy can be taught ${ }^{2}$ :

against the background of increased global mobility and the need to communicate effectively across cultures, the development of Emotional Intelligence (EI) is of growing importance to those involved in intercultural education. There are important theoretical synergies between EI, which is comprised of components such as self-awareness, self-regulation, motivation, empathy and social skills (Goleman 1998), and models of intercultural competence (IC) commonly utilized in intercultural education [...]. In particular, $[\ldots]$ empathy has recently attracted attention from new perspectives (Epley 2015; Bloom 2016; Breithaupt 2017a, 2017b) (Guntersdsorfer \& Goulbeva 2018: 54).

In all interpersonal interactions, interlocutors must be able to interpret and to understand emotional cues of others while at the same time regulate their own internal experience of emotion and how it is expressed through non-verbal and verbal communication. These processes and abilities are excepionally important in intercultural communication since the misreading of emotional cues can lead to misunderstandings. Furthermore, this is

1 For "Intercultural education" I referred to the UNESCO guidelines for Intercultural Education, written by the Section of Education for Peace and Human Rights, Division for the Promotion of Quality Education, Education Sector. The introduction opens as follows: "In a world experiencing rapid change, and where cultural, political, economic and social upheaval challenges traditional ways of life, education has a major role to play in promoting social cohesion and peaceful coexistence. Through programmes that encourage dialogue between students of different cultures, beliefs and religions, education can make an important and meaningful contribution to sustainable and tolerant societies. Intercultural Education is a response to the challenge to provide quality education for all. It is framed within a Human Rights perspective as expressed in the Universal Declaration of Human Rights (1948): 'Education shall be directed to the full development of human personality and to the strengthening of respect for human rights and fundamental freedoms. It shall promote understanding, tolerance and friendship among all nations, racial and religious groups, and shall further the activities of the United Nations for the maintenance of peace" ${ }^{\prime \prime}$ https://unesdoc.unesco.org/ark:/48223/ pf0000147878 (consulted on 24/08/2019).

2 "At the American Association of Teachers in Foreign Languages (ACTFL) conference in 2016, a notable incident occurred when a scholar called-out in a self-confident voice: 'Well, you cannot teach empathy!' In the crowded session, which was attended by more than a hundred people addressing the importance of an intercultural approach in foreign language teaching, nobody openly disagreed with this statement" (Guntersdorfer \& Golubeva 2018: 58). 
true because empathising with others who may have different values and perspectives can be difficult (Breithaupt 2017a: 18-21). Empathy can help to foreground abilities that, in turn, support individuals to manage the emotional challenges of interpersonal relations.

\section{Theoretical foundations}

It is clearly beyond the scope of this article to attempt a comprehensive theoretical synthesis of empathy and intercultural competence; I will instead try to point out pivotal ideas from work that has addressed empathy within intercultural education.

\section{2a. Empathy: Ivett Guntersdorfer's and Irina Golubeva's studies}

In "Emotional Intelligence and Intercultural Competence: Theoretical Questions and Pedagogical Possibilities" (2018) Ivett Guntersdorfer and Irina Golubeva interestingly review work which has focused on empathy ${ }^{3}$. Besides citing Daniel Goleman's book Emotional Intelligence (1995), they refer to the revised meaning of empathy by John D. Mayer and Peter Salovery (1997: 10), who initially defined it (1990: 189):

Emotional Intelligence involves the ability to perceive accurately, appraise and express emotion; the ability to access and/or generate feelings when they facilitate thoughts; the ability to understand emotion and emotional knowledge; and the ability to regulate emotions to promote emotional and intellectual growth.

This conceptualisation is seen as particularly relevant for intercultural education since "it validates emotion as a source of thinking and makes explicit the importance of being able to analyze emotion as a way of deepening understanding of the self and other" (Guntersdorfer \& Golubeva 2018: 55). Paul Bloom (2016: 16) defines empathy as "the act of coming to experience the world as you think someone else does". Empathy is viewed as the disposition that enables one to put her/himself in another's place, and consequently be able to understand or judge others' emotions and share the feelings of another person. Michael Byram (1989: 89) states that empathy is more demanding than tolerance in that "it requires understanding, an activity rather than a passive acceptance; it requires change of viewpoint, which has to be worked towards, engaged with"4.

Guntersdorfer and Golubeva start their analysis by reflecting on the German word for empathy, Mit-Erleben "with-living, co-experience" (Breithaupt 2017b: 15). This concept is echoed in the above-mentioned definition of empathy given by Bloom. The idea

\footnotetext{
3 Guntersdorfer and Golubeva distinguish between Cognitive empathy (understanding), Emotional empathy (emotional response) and Intercultural empathy (others' perception of events / situations).

4 Focusing on the European perspective, Byram refers to the three volumes Reference Framework of Competences for Democratic Culture, Council of Europe, and indicates the value of empathy, listed among the skills in the model of competences: autonomous learning skills; analytical and critical thinking skills; skills of listening and observing; empathy; flexibility and adaptability; linguistic, communicative and plurilingual skills; cooperation skills; conflict-resolution skills (keynote speech at the conference "Educating the Global Citizen. International Perspectives on Foreign Language Teaching in the Digital Age", held in Ludwig-Maximilians-Universität, Munich in 25-28 March 2019).
} 
of "with-living, co-experience" has an emotional/affective dimension, which includes "the ability to access and/or generate feelings when they facilitate thoughts; the ability to understand emotion and emotional knowledge" (Mayer \& Salovery 1997: 10). We can deduce that without empathy "the ability to regulate emotions, cope and react appropriately in an intercultural encounter (or in any kind of successful interpersonal interaction) would not be possible" (Guntersdorfer \& Golubeva 2018: 57).

Lisa Hollingsworth, Mary J. Didelot and Judith O. Smith (2003: 139) state that 10\% of the hate crimes reported in the US occur within schools, and argue that it is the role of the educator to teach empathy to students because it cannot be assumed that these skills are being addressed within the family setting. Expressing care for another is not an innate ability inherently present in some more than others, but rather a skill that can be taught and nurtured through a supportive educational environment. Helen Riess (2017), in her role as director of the empathy and relational science program at Massachusetts General Hospital, recently developed a series of online courses aimed at training physicians on connecting more effectively with people. According to her research, empathy is a mutable and teachable human competency.

Taking into consideration this research, Guntersdorfer and Golubeva (2018) argue that empathy should be taught since it is a desirable quality in many work-places; schools and university campuses are now much more diverse (ethnically, culturally, economically, socially); empathy is important in developing intercultural competence because it helps taking an ethnorelative view of cultural phenomena (Deardoff 2006):

We believe that it is important for the field of intercultural education to take up [Helen Riess's] insights to expand the possibilities for systematically incorporating activities and materials to enhance empathy and other aspects of emotional intelligence for intercultural communication [...]. In terms of classroom practice, we believe it is advantageous to address empathy and other aspects of EI without an intercultural focus in the first instance. For example, teachers can help students reflect on the general role of empathy in human emotional functioning and relationship management, such as by drawing attention to how humans experience and perceive emotions (Guntersdorfer \& Golubeva 2018: 58).

Nicholas Epley (2015) and other social psychologists affirm that perspective-taking alone is not enough. Instead of "taking-perspectives" (implicitly tracing observed behaviours to intentions), they encourage to consider "getting-perspectives", meaning the verbalisation and the verification of our perceived cues (Johnson \& Bechler 1998; Ames, Benjamin \& Brockner 2012; Epley 2015: 180-181). Referring to these studies, Guntersdorfer and Golubeva emphasise the importance of meta-cognitive tasks when addressing empathy in

5 Recently, scholars have also explored the "dark side" of empathy, specifically Jesse Prince (2011), Paul Bloom (2016) and Fritz Breithaupt (2017b) warning about assigning only positive attributes to empathy, which can be used for manipulative instrumentalisation in intercultural situations with an unev distribution of power between the interlocutors. In this respect Bloom writes: "Empathy is like cholesterol with a good type and a bad type" (2016: 16). 
the intercultural communication classroom, facilitating opportunities in which students can gain experience in relating emotions and spending more time on personal reflections.

\begin{abstract}
Once a certain amount of awareness has been raised regarding the nature of empathy, students can be encouraged to consider the cultural variability of emotional experience, the challenges of interpreting emotional clues across cultures, and the role that empathy plays in increasing one's attentiveness to the effect of emotion on intercultural communication [...] students can be encouraged to consider how empathy helps individuals with interpreting and relating across cultural boundaries (Byram 1997) and using dialogue around emotional experience to communicate effectively and appropriately in intercultural contexts (Deardoff 2006) (Guntersdorfer \& Golubeva 2018: 59).
\end{abstract}

Teachers can experiment with creative ways of helping students to become more attuned to the ways in which individuals experience and communicate emotions. "[T]here is a clear role for the teacher to create opportunities for students not only to empathise with individuals from diverse backgrounds but also to be able to formulate one's perceptions and seek to understand emotions in dialogue with others" (Guntersdorfer \& Golubeva 2018: 60).

\title{
2b. Intercultural competence and intercultural citizenship: Michael Byram
}

There is a synergy with work conducted by Michael Byram (1997) and Darla K. Deardorff (2006) in relation to empathy. Byram's (1997) notion of "interpreting and relating" underlines that intercultural competence is not a form of static knowledge that resides within each individual, but rather is something that is achieved as interlocutors actively interpret linguistic and non-linguistic messages and draw on cultural knowledge to enhance common ground. Emotional cues are necessarily embodied within linguistic and non-linguistic messages and are therefore a core part of the meaning-making process which requires to be negotiated. "Related to this, Deardoff (2006) emphasises the importance of empathy and taking ethnorelative view of cultural phenomena in developing intercultural competence, which she sees primarily in terms of interacting effectively and appropriately" (Guntersdorfer \& Golubeva 2018: 55).

Byram (1997) was one of the first researchers to define intercultural competence. He argued that when people from other languages and/or cultures interact in a social context, they contribute with what they know about their own country, but also with what they know and think of people from other cultures. In this sense, both knowledge and attitude are important and they are affected by the processes of intercultural communication, which, in his words, refer to "the skills of interpretation and establishing relationships between aspects of the two cultures" and "the skills of discovery and interaction" (Byram 1997: 33). In order to organise the intercultural dimension, which consists of sustaining interaction and building communication for the development of intercultural skills, we firstly need to offer students the opportunity to build relationships and develop communicative tools, while at the same time helping them to reflect on different ways of doing things and the ability to accept different views and opinions. Intercultural competence consists of a "set of cognitive, 
affective, and behavioural skills and characteristics that support effective and appropriate interaction in a variety of cultural contexts" (Bennett 2008: 16).

An ever-increasing although challenging objective in teaching foreign languages, cultures and literatures is the development of intercultural citizenship, which envisions learners as working actively to deal with world issues (Leask 2015: 17) while tackling them in context specific settings (Porto \& Byram 2015: 24). Intercultural Citizenship integrates the pillar of intercultural communicative competence from foreign language education with the emphasis on civic action in the community from citizenship education (Porto 2014).

The concept of "intercultural citizenship" (IC), which was introduced by Byram (2008), is postulated as a learning outcome to guide curriculum designers and teachers in school and higher education. [...]. It is parallel to other concepts such as "global citizenship", "intercultural competence", or "cultural awareness", which are commonly used in education [...] (Wagner \& Byram 2017: 1) .

In Byram's recent intercultural citizenship construct he focuses on the concept of active citizenship, "being involved in the life of one's community, both local and national" (Wagner \& Byram 2017: 3). Intercultural citizenship is instrumental in promoting the development of foreign language speaking citizens who are able to act and interact in international contexts effectively, through active citizenship implemented through civic actions in their own national communities (Porto, Houghton \& Byram 2017: 6)7. Intercultural citizenship "occurs when people who perceive themselves as having different cultural affiliations from one another interact and communicate, and then analyze and reflect on this experience and act on that reflection by engaging in civic or political activity" (Bryam, Golubeva, Hui \& Wagner 2017: 9).

2c. The creation of an alternative learning space from Edward Soja's 'thirdspace': virtual exchange The debate on the perception of space has been particularly lively over the last five decades. In 1974 in La production de l'espace Henri Lefebvre (1901-1991) considered social space, in an attempt to establish the importance of 'lived' experiences; he argued that geographical space is fundamentally social. Lefebvre implies that 'absolute space' cannot exist because it is colonised by social activity. Every society produces its own space, which is a realm of social relations. In 1989 Edward Soja (1940-2015) referred to Lefebvre, and in his book Postmodern Geographies: The Reassertion of Space in Critical Social Theory confirmed the importance

\footnotetext{
6 In particular, Byram's concept of intercultural citizenship entails: learning more about one's own country by comparison; learning more about 'otherness' in one's own country (especially linguistic/ethnic minorities); becoming involved in activities outside school; making class-to-class links to compare and act on a topic in two or more countries (Byram 2008: 130).

7 Wagner's and Byram's most recent definition of intercultural citizenship follows: causing/facilitating intercultural citizenship experience, which includes activities of working with others to achieve an agreed end; analysis and reflection on the experience and on the possibility of further social and/or political activity; thereby creating learning that is cognitive, attitudinal, behavioural change in the individual; and a change in self-perception, in relationships with people of different social groups (Porto, Houghton \& Byram 2017: 3-4).
} 
of the study of space. He contended that our current environment is, before all else, a social construction of space. Referring to Lefebvre and Michel Foucault (1926-1984), in Thirdspace (1996) Soja criticised the two prevailing modes of analysing space, a dominant approach that interpreted the spatiality of our lives primarily in terms of the configuration of material forms, mappable "things in space", and a more subjective alternative that emphasised mental representations of those material mappable forms. Lefebvre called these two modes "conceived space" (professional and theoretical; cartographers, urban planners, property speculators) and "perceived space" (of everyday social life and commonsensical perception). Lefebvre proposed a third mode which he called 'lived space', affirming that the person who is fully human also dwells in a "lived space" of the imagination. Similarly, Foucault noted these two dominant modes of thinking about space, and suggested they were insufficient to understand the simultaneously real and imagined "other" spaces in which we live, in which our individual biographies are played out, in which social relations develop and change, and in which history is made. In a lecture held by Foucault in 1967 on "Des espaces autres", and in an essay of the same title published in 1984, he described space as an active and heterogeneous medium. What Lefebvre called "lived space", Foucault called "espaces autres", "other" spaces, significantly different spaces, a counter-space that exists outside the usual order of things. Soja's concept of "thirdspace" is derived from Foucault's and Lefebvre's notion of a counter-space, Lefebvre's "lived space" and Foucault's "espaces autres". He uses the concept of "thirdspace" to refer to a specific way of thinking about and interpreting socially produced space. It is a way of thinking that sees the spatiality of our lives, the human geographies in which we live, as having the same scope and critical significance as the historical and social dimensions of our lives ${ }^{8}$.

In Foucault's lecture of 1967 on "Des espaces autres", where the interest is directed towards space as a "cultural construct" and "social product", we could trace back the actual origin of the concept of "spatial turn", a cultural trend over the last few decades which has been responsible for in the reinsertion of space into the social sciences and humanities (Warf \& Arias 2009). If we consider the "spatial turn" in its pedagogical dimension, and Foucault's, Lefebvre's and Soja's conceptualisation of a counter-space, we can detect a possible connection between this counter-space and the development of an alternative learning space, enhanced and shaped by social relationships, a "relational counter-space" ${ }^{9}$. The relevance of foreign languages and literatures has increased immensely in the education of critical and collective, local and global citizens; the necessity of expanding learning environments through the conception and allocation of further spaces for inter-linguistic and

\footnotetext{
8 In Seeking Spatial Justice (2010) Soja writes: "For at least the past century, thinking about the interrelated historical and social aspects of our lives has tended to be much more important and widely practiced than emphasizing a pertinent critical spatial perspective [...]. In recent years, however, the way we interpret the relation between the social, the historical, and the spatial aspects of our lives has begun to change in significant ways. A new and different approach to thinking about space and spatiality has been emerging in conjunction with what some have described as a spatial turn affecting nearly all the human sciences" (2010: 3).

9 The idea of relational counter space has been interestingly discussed by Sabine Knierbein in "Public space as relational counter space: scholarly minefield or epistemological opportunity?" (Tornaghi \& Knierbein 2015).
} 
intercultural interactions is now evident. Ways to achieve alternative, meaningful environments in teaching second and foreign languages and cultures can be experimented through the creation of "counter-spaces", spaces for inter-linguistic and intercultural interactions enhanced and shaped by the social relationships and spatial practices that unfold in and through that space, and which could be designed through cross-institutional collaborations and virtual exchanges between students. A space which is built in terms of the lived experiences of people can foster empathy.

Why virtual exchange? Over the course of the last decade technology appears to have become the primary means through which new spaces of educational interactions are created. Telecollaboration, Online Intercultural Exchanges or Virtual Exchange ${ }^{10}$, are terms used to refer to the engagement of groups of learners engaged in online intercultural interactions and collaboration projects with partners from other cultural contexts or geographical locations as an integrated part of their educational curriculum. In recent years, approaches to virtual exchange have evolved in different contexts and different areas of education, and these approaches have had very diverse organisational structures and pedagogical objectives (O'Dowd 2018) $)^{11}$. There is an increasing amount of literature on initiatives related to joint international online learning environments that use synchronous video communication tools to teach a foreign language. The perceived outcomes illustrate positive results both in terms of language acquisition and in terms of learning experience for students. Virtual exchange is widely seen as having a high potential of removing physical and mental boundaries between learners, and offering opportunity for cross-national dialogue. Overall, virtual exchange aims to foster the development of foreign language skills but also of intercultural competence through culture-based activities. Besides promoting language learning, "good" telecollaborative tasks (see Byram, Golubeva, Hui \& Wagner 2017) foster the intercultural analysis of the practices and values of the cultures of the groups involved in the virtual exchanges. Robert O’Dowd recently wrote that

although progress might be slow, it is clear that, in a world increasingly characterised by the rise of right-wing extremism, religious fanaticism, and populist political movements, virtual exchange will have an important role to play as educators strive to develop active, informed, and responsible citizens who are tolerant of difference and who are actively engaged in political and democratic processes (2018: 21).

The intercultural citizenship-related dimension of virtual exchange envisions learners as active global agents able to tackle world challenges (Leask 2015: 17). Here, telecollabora-

\footnotetext{
10 I will follow Robert O'Dowd's proposal to use Virtual Exchange as an umbrella term, in R. O'Dowd (2018: 3).

11 "The term 'telecollaboration' has been used to describe many different types of online exchanges, ranging from loosely guided language practice of the target language (e.g. online conversations in text or oral chat) to elaborately designed project-based collaborative exchanges" (Dooly \& O'Dowd 2018: 17). "In recent years, approaches to virtual exchange have evolved in different contexts and different areas of education, and these approaches have had, at times, very diverse organisational structures and pedagogical objectives" (O'Dowd 2018: 1).
} 
tive tasks are expected to foster not only students' foreign language skills and intercultural competence but also learners' engagements with global problems tailored to local contexts: intercultural citizenship education means that learners would be encouraged to act together with others in the world and that those others would be in other countries and speakers of other languages. While engaged in intercultural citizenship-focused virtual exchange, partner groups analyse together topics related to their own societies within an intercultural framework; as a result of the co-participated analysis, each national group plans and carries out a form of civic action in its own community to foster social changes (Porto, Houghton \& Byram 2017: 6): "[language] learners [...] would decide on a project of significance in their community, share ideas and plans with each other, critically analyse the reasons/assumptions in their plans by comparison with the plans of the other group, carry out and report to each other their projects" (Byram et al. 2017: 26). From an intercultural citizenship perspective, it is expected that virtual exchange tasks will foster transformative processes in the students engaged in virtual exchange: as Liddicoat and Scarino suggest "[ $t$ ]he goal of learning is to decenter learners from their pre-exiting assumptions and practices and to develop an intercultural identity through engagement with an additional culture. The borders between self and other are explored, problematized, and redrawn" (2013: 29). These kinds of projects will allow the development of civic actions in local national communities: "[ $t$ ]here is a challenge [...] about how to make linguistic-competence oriented courses not only intercultural but also citizenship-oriented" (Porto, Houghton \& Byram 2017: 237). Central to intercultural citizenship projects is the opportunity given to students to build relationships, to recognise what they think and what they feel and to verbalise their own and others' thoughts and emotions effectively.

\section{A virtual exchange between Italy and the U.S.A.}

Based on the recommendations made by O'Dowd and Ware (2009), O'Dowd (2017, 2018), Byram, Golubeva, Hui and Wagner (2017) and Guntersdorfer and Golubeva (2018) about factors that educators should consider when designing and implementing tasks for virtual exchanges, we created an intercultural project between Italy and the U.S.A. ${ }^{12}$, which will be presented in synthesis; one of the main objectives is building (intercultural) empathy in teaching foreign languages, cultures and literatures. A transnational, telecollaborative project, namely "Language Forward Initiative", will be developed over three years (Autumn 2018 - Spring 2021) at the University of Virginia. Eleven languages programmes, including Italian, are involved in this initiative and each programme has designed a unique virtual place to develop students' cultural and linguistic fluency. In this context, we designed a foreign language acquisition project based on a virtual exchange between Italian Studies, UVa, and a pre-University institution, an Italian upper-secondary school in Milan. Our project created a virtual space as an integrated part of the educational curriculum, parallel to

12 The project was designed by Roberta Trapè (School of Languages and Linguistics, University of Melbourne) and Francesca Calamita (Italian Studies, University of Virginia, the coordinator of the research group on the "Language Forward Initiative", Institute of World Languages). It is supported by a Jefferson Trust Award awarded to the Institute of World Languages in Spring 2018. 
the space-time of traditional class-tuition, which students inhabit with a great degree of autonomy. With regards specifically to course design, we blended face-to-face foreign language lessons with Skype-mediated digital learning. Thirty North American students studying Italian were partnered for two semesters (Autumn 2018 and Spring 2019) with thirty Italian upper-secondary school studying English to talk in dyads in desktop videoconferencing about selected conversational topics through a synchronous video communication tool (Skype). During the virtual exchange, students worked in dyads and met weekly to talk 15/20 minutes in Italian and 15/20 minutes in English. Dialogical interaction, focused on contemporary Italian/ North American cultural topics in authentic, communicative language learning environments, was promoted through specific activities and tasks: information exchange, comparison and analysis, and collaboration and product creation ( $\mathrm{O}^{\prime}$ Dowd \& Ware 2009: 175-178); opinion exchange, decision making, and problem solving.

The project was divided into six Skype meetings over the course of each semester. The creation of joint international online learning spaces offered students the opportunity to talk to distant native speakers of a target language of a similar age. The learners were put in a scenario which required them to both use and produce their knowledge in a meaningful context; they were encouraged to think in a critical and comparative way, while practicing the target language. The out-of-class technology-mediated activities fostered the development of students' speaking and interactional skills and their fluency in the target language. Moreover, they also helped students to build relationships and develop intercultural communicative competence by improving their ability to articulate cultural similarities and differences between Italy and North America through culture-based activities. Thus the intercultural analysis of the practices and values of the cultures of the groups involved in the virtual exchanges was fostered. To cultivate the intercultural dimension, we helped the students to sustain interaction and build communication, to reflect on different ways of doing things and to be capable of accepting different views and opinions. A disposition for critical thinking allowed students and teachers to reflect on messages and explore differences in view, understanding controversies and debates. A focus on empathy provided opportunities for students to become experienced in describing emotions and spending more time on personal reflections. The foundation of the overall project is that of transporting the student in a virtual relational "counter-space" in which "learners examine phenomena and experience their own cultural situatedness while seeking to enter into the cultural worlds of others" (Scarino 2014: 391) and learning to reflect on their own and others' thoughts and emotions, and being able to verbalise them effectively. In this digital space, students are enabled and encouraged to leave their ordinary learning environment and to enter, on a weekly basis, a new and far more personalised space for cross-cultural and inter-linguistic exchange.

Before the Skype meetings commenced, students were given a list of weekly cultural topics, carefully sequenced, to be discussed during the Virtual Exchange ${ }^{13}$. The topics were chosen to foster students' reflections on culture-specific issues including stereotyping, in-

13 In order to integrate face-to-face instructions and online learning effectively, the digital learning project provided UVa and Italian students with the opportunity to converse with distant Italian/North American students about culture-specific topics interrelated with the topics dealt within in-class face-to-face instruction. 
tercultural competence, empathy and emotions. A challenging objective for the remaining two academic years (from Autumn 2019 to Spring 2021) is that of the development of intercultural citizenship-focused virtual exchange, where both groups of students plan and carry out civic actions in their local communities. It encourages students to become global citizens ready to act and interact in multilingual and international contexts through active citizenship (Wagner \& Byram 2017: 3). This is done by taking students out of their comfort zone and engaging them in real-world tasks and contributions through an intercultural citizenship project of significance in their own communities: after focus groups discussions with students, we have chosen to deal with gender equality and the use of gender-inclusive language. As such, the objectives are: learning beyond the classroom's walls through virtual exchange and contact with local organisations (gender equality and gender-based violence); community engagement; intercultural communicative competence; intercultural active citizenship; solidarity and empathy; motivation and engagement (meaningful learning); linguistic, digital, interpersonal creativity.

This intercultural citizenship virtual exchange consists of two main tasks (in-group and out-group): the former is developed within the group, and the latter through the trans-Atlantic virtual exchange. Both groups of students undertake this two-step task. First, each group of students has to develop and negotiate in class a shared position within the group in class on the issue of gender equality and gender-inclusive language (focus groups; students' written reflections; interview with local organisations and citizens). A task sequence has been structured to invite students to reflect on the chosen topic and to be able to verbalise their own and others' emotions ${ }^{14}$; reflective tasks concentrate on developing negotiation skills. As a second step, students have to discuss the topic with their peers across the Atlantic Ocean. At the beginning students are provided with the selected topic and materials, and then are asked to explore them on their University / School platforms (definitions, articles and videos on campaigns for gender equality, and for the use of inclusive language or against it). The task is to analyse the documents uploaded to websites. The topics are presented within the group in class (Self-Reflection 1) and at this point the analysis starts: students debate the different views on gender equality and inclusive language in their countries in small teams within the 'country' group, and again within the whole group. They structure and use ethnographic interviews to investigate the issue in their respective language speaking settings (local organisations, citizens). The next step is that of developing and negotiating a shared analysis and plan actions locally (Self-Reflection 2); the students present in virtual exchange their own group's views on the issue talking in dyads and in a final group-to-group encounter; students subsequently consider the other group's analysis and discuss others' views; they will reflect on others' views (Self-Reflection 3); students create collaborative products (namely: a website; lessons within their own institution and/or in the community; a play) to bring the issue of gender equality and gender-inclusive language into their local communities. This multimodal project allows students to engage critically with Italian and North American media and to become sensitive to the gendered politics of language (Self-Reflec-

14 The task sequence follows some of the indications suggested by Guntersdorfer and Golubeva (2018). 
tion 4). Students will be asked ultimately to evaluate the project, including self-evaluation, and by providing feedback ${ }^{15}$.

\section{Conclusion}

Ideally, this project creates spaces where students' social participation and engagement is stimulated and officially valued, and where international relationships with students living in another country, and links with the local community are formed. It aims to create effective virtual exchanges of international teams, in an effort to address real current social problems in innovative ways. It brings critical issues of today's world to the fore in the teaching of foreign languages, cultures and literatures, and empowers students to actively reflect upon their role in a democratic society. A focus on empathy and solidarity encourages students to recognise their emotions and to express them, activating their ability to regulate emotions, cope, act and interact effectively in intercultural encounters. It makes them aware of how empathy can help them with interpreting and relating across cultures, and by using dialogue around emotional experience to communicate effectively and build relationships in intercultural contexts.

\section{BIBLIOGRAPHY}

Ames, Daniel, Lily Benjamin Maissen \& Joel Brockner. 2012. The Role of Listening in Interpersonal Influence. Journal of Research in Personality, 46: 345-349.

Bennett, Janet M. 2008. Transformative Training: Designing Programs for Culture Learning. Michael A. Moodian ed. Contemporary Leadership and Intercultural Competence: Exploring the Cross-cultural Dynamics within Organizations. Thousand Oaks (CA): Sage, 95-110.

Bloom, Paul. 2016. Against Empathy. London: Bodley Head.

Breithaupt, Fritz 2017a. Kulturen der Empathie. 5. Auflage. Berlin: Suhrkamp.

Breithaupt, Fritz 2017b. Die Dunklen Seiten der Empathie. 3. Auflage. Berlin: Suhrkamp.

Byram, Michael. 1989. Cultural Studies in Foreign Language Education. Clevedon: Multilingual Matters.

Byram, Michael. 1997. Teaching and Assessing Intercultural Communicative Competence. Clevedon: Multilingual Matters.

Byram, Michael. 2008. From Foreign Language Education to Education for Intercultural Citizenship. Essays and Reflections. Clevedon-Buffalo-Toronto: Multilingual Matters.

15 The project was designed according to the "Blended learning" and "Knowledge-building" approaches. Blended learning can overcome the lecturer-centered lessons creating a learning environment in which the production of knowledge can be shared between the teacher and the learner; this opens up space for the learners to bring into the lesson their own perspective and culture (Gruba \& Hinkelman 2012). The idea behind knowledge-building applied to the classroom is that knowledge can be an experience shared by the teacher and the students and it leads to the creation of ideas which can have a "public life", a social utility beyond the classroom. With the knowledge-building approach the final result is obtained through the active and collaborative efforts of the teacher with the students, who have an active role in the learning process and play a fundamental part in it. The aim is to create an environment where the focus is not for the students to learn notions but to create ideas (Bereiter \& Scardamalia 2014; Kern \& Develotte 2018). 
Byram, Michael. 2009. Intercultural Competences in Foreign Languages. The Intercultural Speaker and the Pedagogy of Foreign Language Education. D. K. Deardorff ed. The SAGE Handbook of Intercultural Competence. London: SAGE Publications, 321-332.

Byram, Michael. 2014. Twenty-five Years on From Cultural Studies to Intercultural Citizenship. Language, Culture and Curriculum, 27, 3: 209-225.

Byram, Michael, Irina Golubeva, Han Hui \& Manuela Wagner eds. 2017. Introduction. From Principles to Practice in Education for Intercultural Citizenship. Bristol-Buffalo-Toronto: Multilingual Matters, 21-35.

Deardorff, Darla K. 2006. The Identification and Assessment of Intercultural Competence. Journal of Studies in International Education, 10, 3: 241-266.

Deardorff, Darla K. \& Lily A. Arasaratnam-Smith eds. 2017. Intercultural Competence in Higher Education International Approaches, Assessment and Application. New York: Routledge.

Epley, Nicholas. 2015. Mindwise. Why we Misunderstand What Others Think, Believe, Feel, and Want. New York: Vintage Books.

Foucault, Michel. 1986 [1984]. Des espaces autres in Architecture, Mouvement, Continuité, 5 (October): 46-49; “Other Spaces: Utopias and Heterotopias" translated by Jay Miskowiec. Diacritics, 16, 1 (Spring): 22-27.

Goleman, Daniel. 1995. Emotional Intelligence. London: Bloomsbury.

Goleman, Daniel. 1998. Working with Emotional Intelligence. New York: Bantam Books.

Guntersdorfer, Ivett \& Irina Golubeva. 2018. Emotional Intelligence and Intercultural Competence: Theoretical Questions and Pedagogical Possibilities. Intercultural Communication Education, 1, 2: 54-63.

Hollingsworth, Lisa A., Mary J. Didelot \& Judith O. Smith. 2003. REACH Beyond Tolerance: A Framework for Teaching Children Empathy and Responsibility. The Journal of Humanistic Counseling, 42, 2 (Fall): 139-151.

Johnson, Scott D. \& Curt Bechler. 1998. Examining the Relationship between Listening Effectiveness and Leadership Emergence: Perceptions, Behaviors, and Recall. Small Group Research, 29: 452-471.

Knierbein, Sabine. 2015. Public Space as Relational Counter Space: Scholarly Minefield or Epistemological Opportunity? Tornaghi Chiara \& Sabine Knierbein eds. Public Space and Relational Perspectives. New Challenges for Architecture and Planning. Abingdon: Francis \& Taylor, 42-63.

Leask, Betty. 2015. Internationalising the curriculum. Abingdon: Routledge.

Lefebvre, Henri. 1991 [1974]. La production de l'espace. Paris: Éditions Anthropos; The Production of Space, translated by D. Nicholson-Smith. Oxford: Blackwell.

Liddicoat, Anthony J. \& Angela Scarino. 2013. Intercultural Language Teaching and Learning, Oxford: Wiley-Blackwell.

Mayer, John D. \& Peter Salovey. 1997. What is Emotional Intelligence? Peter Salovey \& David J. Sluyter eds. Emotional Development and Emotional Intelligence. New York: Basic Books. O'Dowd, Robert. 2006. Telecollaboration and the Development of Intercultural Communicative Competence. Berlin: Langenscheidt.

O'Dowd, Robert. 2017 [ $3^{\text {rd }}$ ed.]. Online Intercultural Exchange and Language Education. 
Thorne Steven L. \& May Stephen eds. Language, Education and Technology. Encyclopedia of Language and Education. Cham: Springer, 1-12.

O'Dowd, Robert. 2018. From Telecollaboration to Virtual Exchange: State-of-the-art and the Role of UNICollaboration in Moving Forward. Journal of Virtual Exchange, 1: 1-23.

O’Dowd, Robert \& Paige Ware. 2009. Critical Issues in Telecollaborative Task Design. Computer Assisted Language learning, 22, 2: 173-188.

O’Dowd, Robert \& Tim Lewis. 2016. Online Intercultural Exchange: Policy, Pedagogy, Practice. New York: Routledge.

Porto, Melina. 2014. Intercultural Citizenship Education in an EFL Online Project in Argentina in Language and Intercultural Communication, doi:10.1080/14708477.2014.890625.

Porto, Melina \& Michael Byram. 2015. A Curriculum for Action in the Community and Intercultural Citizenship in Higher Education. Language, Culture and Curriculum, 28: 226-242. Porto, Melina, Ann Houghton Stephanie \& Michael Byram. 2017. Intercultural Citizenship in the (Foreign) Language Classroom. Language Teaching Research, 22, 5: 484-498, doi: $10.1177 / 1362168817718580$.

Riess, Helen. 2017. The Science of Empathy. Journal of Patient Experience, 4, 2: 74-77.

Salovey, Peter \& John D. Mayer. 1990. Emotional Intelligence in Imagination, Cognition, and Personality, 9, 3: 185-211.

Scarino, Angela. 2014. Learning as Reciprocal, Interpretive Meaning-Making: A View from Collaborative Research into the Professional Learning of Teachers of Languages. The Modern Language Journal, 98, 1: 368-401.

Soja, Edward W. 1989. Postmodern Geographies: The Reassertion of Space in Critical Social Theory. London: Verso.

Soja, Edward W. 1996. Thirdspace: Journeys to Los Angeles and Other Real-and-Imagined Places. Oxford: Blackwell Publishers.

Soja, Edward W. 2010. Seeking Social Justice. Minneapolis-London: University of Minnesota Press.

Wagner, Manuela \& Michael Byram. 2017. Intercultural Citizenship. Y. Y. Kim ed. The International Encyclopedia of Intercultural Communication. Oxford: Wiley, 1-6.

Warf, Barney \& Santa Arias eds. 2009. The Spatial Turn: Interdisciplinary Perspectives. New York-London: Routledge.

Roberta Trapè is an Honorary Fellow of the School of Languages and Linguistics at The University of Melbourne. She has worked extensively on the theme of Australian travel to Italy in contemporary Australian fiction, non-fiction and poetry. The research she has carried out so far has shifted between theory - travel writing, notions of space and movement in contemporary society including the migration experience - and close communication with contemporary Australian writers who have lived or travelled in Italy and written about it in the last three decades. She has written on notions of space in narrating history, and examined travel ideals of Italy in food in North American films. Her ongoing research explores foreign language pedagogy, in particular learning spaces/places in Virtual Exchange, and Intercultural Citizenship.

r.trape@unimelb.edu.au 